\title{
Schmidt syndrome (Autoimmune polyendocrinopathy syndrome type 2) in a 10 year old child
}

\author{
G R Sunilkumar ${ }^{1}$, R Sujatha ${ }^{2}$, Mohammed Hidayathulla ${ }^{1}$
}

Sri Lanka Journal of Child Health, 2014; 43(4): 239-241

(Keywords: Autoimmune polyendocrinopathy syndrome type 2; APS type 2; Schmidt syndrome; child)

\section{Case report}

A 10 year old girl, born to non-consanguineous parents, presented with a history of fever and cough since 3 days, fainting one week back and tiredness since one week. There was a history of progressive darkening of the skin since the age of 4 years following an attack of febrile illness. Mother also gives a history of the child having generalized weakness, loss of appetite and decreased interest in the surroundings. There was no history of chronic medication, headache or vomiting.

On examination, the child looked sick and was dehydrated. Her pulse rate was 90 beats per minute and weak, blood pressure $70 / 50 \mathrm{mmHg}$, respiratory rate 20 cycles/minute and oxygen saturation $98 \%$ in room air. Her height was $142 \mathrm{~cm}$ and weight $27 \mathrm{~kg}$. On general examination, she was noted to have generalised hyperpigmentation along with mucosal and gum pigmentation and palmar crease pigmentation (Figures 1,2 and 3). On auscultation there were bilateral crepitations with normal breath sounds and others systems were normal.

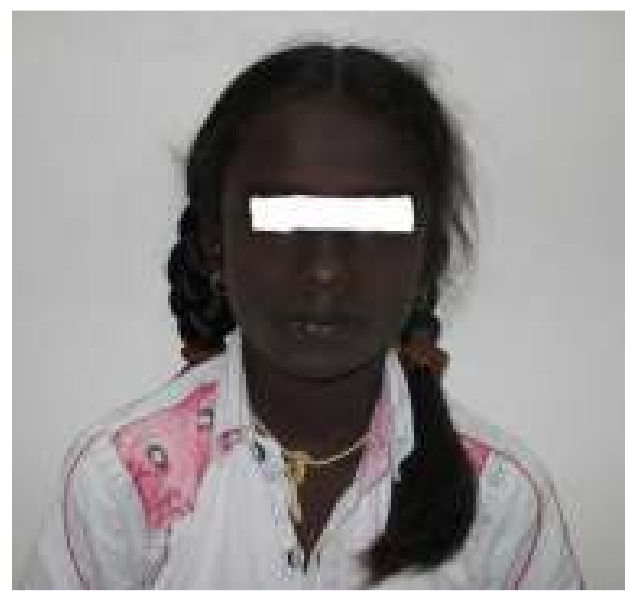

Figure 1: Generalised hyperpigmentation

\footnotetext{
${ }^{1}$ Assistant Professor, ${ }^{2}$ Professor, Sapthagiri Institute of Medical Sciences, Bangalore, Karnataka, India
}

(Received on 10 October 2013: Accepted after revision on 22 November 2013)

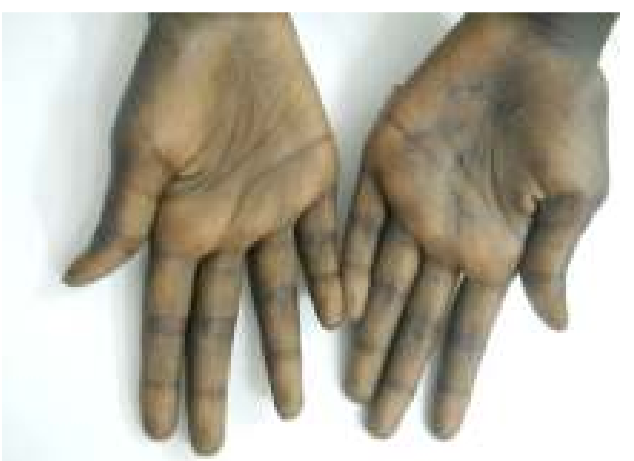

Figure 2: Pigmentation of palmar creases

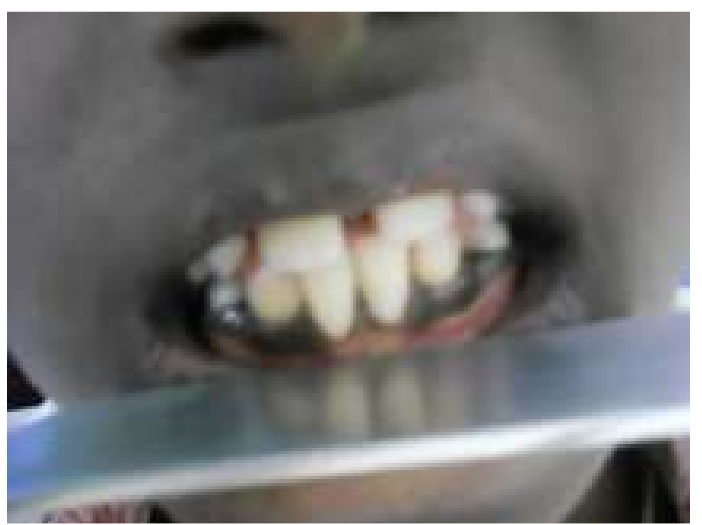

Figure 3: Gum pigmentation

The haemoglobin level was $10.6 \mathrm{~g} \%$. The white blood cell count was 7,000/cu mm (N39, L49, E8, M4\%). The erythrocyte sedimentation rate was $45 \mathrm{~mm}$ in $1^{\text {st }}$ hour. The platelet count was $200,000 / \mathrm{cu} \mathrm{mm}$. The peripheral blood picture was normocytic and hypochromic with a relative lymphocytosis. The serum sodium was $134 \mathrm{mEq} / \mathrm{L}$, serum potassium $4.1 \mathrm{mEq} / \mathrm{L}$ and serum chloride $101 \mathrm{mEq} / \mathrm{L}$. The serum calcium was $10.2 \mathrm{mg} / \mathrm{dl}$ and serum phosphorus $5.6 \mathrm{mg} / \mathrm{dl}$. The blood urea was $24 \mathrm{mg} / \mathrm{dl}$ and the serum creatinine $0.5 \mathrm{mg} / \mathrm{dl}$. The chest $\mathrm{x}$-ray showed microcardia. The Mantoux test was negative. A computed tomography scan of abdomen showed minimal right sided pleural effusion and a normal adrenal gland. The serum aldosterone was $6.9 \mathrm{ng} / \mathrm{dl}$ (normal range for $10-15$ year olds $2-22 \mathrm{ng} / \mathrm{dl}$ ). The $8 \mathrm{am}$ serum cortisol was $0.39 \mu \mathrm{g} / \mathrm{dl}$ (normal range 6.2- 
$19.4 \mu \mathrm{g} / \mathrm{dl})$. The serum ACTH level was greater than $1250 \mathrm{pg} / \mathrm{ml}$ (normal up to $46 \mathrm{pg} / \mathrm{ml}$ ). The plasma renin level was $5.1 \mathrm{ng} / \mathrm{ml} /$ hour (normal range 0.5 $3.3 \mathrm{ng} / \mathrm{ml} /$ hour). The serum T3 was $0.99 \mathrm{ng} / \mathrm{ml}$ (normal range $0.4-2.4 \mathrm{ng} / \mathrm{ml}$ ), the serum T4 $7.15 \mu \mathrm{g} / \mathrm{ml}$ (normal range $4-15 \mu \mathrm{g} / \mathrm{ml}$ ) and the serum $\mathrm{TSH}$ $35.19 \mu \mathrm{IU} / \mathrm{ml}$ (normal range 0.2-8.1 $\mu \mathrm{IU} / \mathrm{ml}$ ). The thyroid peroxidase antibody level was $114 \mathrm{IU} / \mathrm{ml}$ (normal range $0-50 \mathrm{IU} / \mathrm{ml}$ ). The serum parathyroid hormone level was $78.2 \mathrm{pg} / \mathrm{ml}$ (normal range 14$72 \mathrm{pg} / \mathrm{ml})$

We made a diagnosis of lower respiratory tract infection with hypotension secondary to adrenal insufficiency. We evaluated the child for other endocrine functions and found hypothyroidism. Child was admitted to the paediatric intensive care unit and fluid resuscitation done. Subsequently child was started on antibiotics, levothyroxine and hydrocortisone. Child improved with the treatment and was discharged by 2 weeks with oral hydrocortisone $10 \mathrm{mg} / \mathrm{m}^{2} /$ day and levothyroxine $100 \mathrm{mcg} / \mathrm{day}$. On follow up after 6 months, the child was noted to have an increase in height and weight and the mother also noticed an improvement in her scholastic performance and socializing skills.

\section{Discussion}

Autoimmune polyendocrine syndromes (APS) are uncommon endocrinopathies typified by the occurrence of at least two glandular autoimmune mediated diseases ${ }^{1}$. APS type 1 usually appears in childhood between 3-5years of age or in early adolescence and is characterized by persistent chronic mucocutaneous candidiasis, adrenal failure and hypoparathyroidism ${ }^{2}$. APS type 2 may occur at any age or sex, but is more common in middle aged females and is characterized by the presence of autoimmune Addison disease in association with either autoimmune thyroid disease and/or type 1 diabetes mellitus ${ }^{3}$. APS type 3 is typically observed in middle-aged women but can occur in persons of any age and shows a direct association of autoimmune thyroid disease and type 1 diabetes mellitus and is found in the absence of Addison disease $^{4}$. APS type 4 is a syndrome characterized by the association of autoimmune combinations not falling into the above categories, for example, Addison's disease with one or more minor components (rheumatoid arthritis, autoimmune liver disease, primary gonadal failure, pernicious anemia, coeliac disease, vitiligo, etc.) excluding other major components of APS types 1,2 and $3^{4}$. APS type 2 is the commonest immunoendocrinopathy syndrome ${ }^{3}$.
Our patient presented with adrenal insufficiency and hypothyroidism and is a case of APS type 2 .

APS type 2 is also known as Schmidt syndrome, after Schmidt who first described the association of Addison disease with thyroid insufficiency in $1926^{5}$. The prevalence of Schmidt syndrome is $1.4-4.5$ per 100,000 population with a female to male ratio of $2.4: 1^{6}$. In patients with APS type 2 , Addison disease is present in $100 \%$ of cases, autoimmune thyroid disease in $69-82 \%$ and type 1 diabetes mellitus in $30-$ $52 \%{ }^{3}$. The pattern of inheritance is polygenic with HLA predominance of DR3, DR4, DQ2, DQ8, DRB1, with variable expressivity and female to male ratio of 3.4: $1^{7}$. Organ specific autoimmune endocrinopathies frequently occur in privileged clusters of association and type 2 is considered one of the most typical. Clinically overt syndrome is considered only the tip of the iceberg since latent forms are much more frequent. Organ specific autoantibody screening in patients with monoglandular endocrinopathy facilitate identifying those who develop APS in future ${ }^{8}$.

A review of the literature revealed few cases of Schmidt syndrome in the paediatric age group. Karamifer et $\mathrm{al}^{3}$ reported an 11 year old boy, a known case of Addison disease who later developed diabetes mellitus and hypothyroidism. Nelson RP et $\mathrm{al}^{5}$ has reported an 11 year old child, a known case of diabetes mellitus with hypoadrenalism and hypothyroidism. In India, Kumar R et $\mathrm{al}^{9}$ has reported a case of a 15 year old boy, a known case of hypothyroidism who presented with diabetic ketoacidosis to the emergency department. He also had a subclinical primary adrenal insufficiency.

Betterle et $\mathrm{al}^{6}$ reviewed 351 patients with APS type 2 . Addison disease was seen in $100 \%$, thyroid autoimmune disease in $82 \%$ and diabetes mellitus in $30 \%$. In a long term follow up study of 360 patients with APS 2 by Dittmar $M$. et $\mathrm{al}^{10}$, autoimmune thyroid disease was seen in $65.6 \%$, diabetes mellitus in $60.9 \%$ and Addison disease in $18.5 \%$. In our case, the child had primary adrenal insufficiency and hypothyroidism. Hypothyroidism was secondary to autoimmune origin as indicated by the high titre of antithyroid antibodies. Anti adrenal antibodies were not done due to economic constraints.

Once a diagnosis of autoimmune disorder of any endocrine gland is made, the physician should look for coexistence of other endocrinal gland dysfunction by a detailed evaluation. 


\section{References}

1. Eisenbarth GS, Gottlieb PA. Autoimmune polyendocrine syndromes. New England Journal of Medicine 2004; 350:2068-79. http://dx.doi.org/10.1056/NEJMra030158

2. Hsieh MC, Chen HD, Du-An Wu. Autoimmune polyendocrinopathy syndromes - A case report. Tzu Chi Medical Journal 2006; 18: 385-8.

3. Karamifar H, Dalili S, Karamizadeh Z, Amirhakimi G, Dalili H. Autoimmune polyendocrinopathy syndrome type 2: An unusual presentation. Acta Medica Iranica 2010; 48(3): 196-7.

4. Basak RC, Chatterjee M, Rassem MW. Autoimmune polyglandular syndrome (type III): Case Report. Kuwait Medical Journal 2007; 39:373-5.

5. Nelson RP, Traisman HS, Deddish RB, Green OC. Schmidt syndrome in a child with diabetes mellitus. Diabetes Care 1978; 1 (1): 37-9. http://dx.doi.org/10.2337/diacare.1.1.37
6. Betterle C, Zanchetta R. Update on autoimmune polyendocrinopathy syndromes. Acta Bio Medica 2003; 74: 9-33.

7. Eisenbarth GS, Gottlieb PA. Medical progressAutoimmune polyendocrinopathy syndromes. New England Journal of Medicine 2004; 350: 2068-79.

http://dx.doi.org/10.1056/NEJMra030158

8. Betterle C, Lazzarotto F, Presotto F. Autoimmune polyendocrinopathy syndrome type 2: The tip of iceberg? Clinical \& Experimental Immunology 2004; 137: 225-33. http://dx.doi.org/10.1111/j.13652249.2004.0256 $\underline{1 . x}$

9. Kumar R, Reddy DVS, Unnikrishnan AG, Bhadada SK, Agrawal NK, Singh SK. Polyglandular autoimmune endocrinopathy in type 2 diabetes. Journal of the Association of Physicians of India 2004; 52: 999-1000.

10. Dittmar M, Kahaly GJ. Autoimmune polyendocrinopathy syndromes: Immunogenetics \& long term follow up. The Journal of Endocrinology \& Metabolism 2003; 88(7): 298392.

http://dx.doi.org/10.1210/jc.2002-021845 